\title{
Platelet CD40 Mediates Leukocyte Recruitment and Neointima Formation after Arterial Denudation Injury in Atherosclerosis-Prone Mice
}

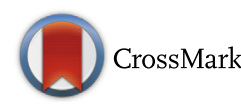

\author{
Rong Jin,${ }^{\star \dagger}$ Adam Y. Xiao, ${ }^{\ddagger}$ Zifang Song, ${ }^{\dagger}$ Shiyong Yu, ${ }^{\dagger}$ Jarvis Li, ${ }^{\S}$ Mei-Zhen Cui, ${ }^{\lceil}$and Guohong Li ${ }^{* \dagger}$
}

From the Departments of Neurosurgery* and Molecular and Cellular Physiology, ${ }^{\ddagger}$ Louisiana State University Health Sciences Center, Shreveport, Louisiana; the Department of Neurosurgery, ${ }^{\dagger}$ the Pennsylvania State University College of Medicine, Hershey, Pennsylvania; the Caddo Magnet High School, ${ }^{\S}$ Shreveport, Louisiana; and the Department of Biomedical and Diagnostic Sciences, ${ }^{\boldsymbol{\top}}$ College of Veterinary Medicine, University of Tennessee, Knoxville, Tennessee

Accepted for publication September 21, 2017.

Address correspondence to Guohong Li, M.D., Ph.D., Pennsylvania State College of Medicine, 500 University Dr, BMR, C3830G, Hershey, PA 17033. E-mail: guohongli@ pennstatehealth.psu.edu.

\begin{abstract}
The role of platelets in the development of thrombosis and abrupt closure after angioplasty is well recognized. However, the direct impact of platelets on neointima formation after arterial injury remains undetermined. Herein, we show that neointima formation after carotid artery wire injury reduces markedly in $\mathrm{CD} 40^{-/-}$ apolipoprotein $\mathrm{E}-$ deficient $\left(\mathrm{apoE}^{-/-}\right.$) mice but only slightly in $\mathrm{CD} 40$ ligand $^{-/-} \mathrm{apoE}^{-/-}$mice, compared with $\mathrm{apoE}^{-/-}$mice. Wild-type and $\mathrm{CD} 40$-deficient platelets were isolated from blood of apoE $\mathrm{E}^{-/-}$and $\mathrm{CD}^{-10^{-/-}} \mathrm{apoE}^{-/-}$ mice, respectively. The i.v. injection of thrombin-activated platelets into $\mathrm{CD} 40^{-/-} \mathrm{apoE}^{-/-}$mice was performed every 5 days, starting at 2 days before wire injury. Injection of wild-type platelets promoted neointima formation, which was associated with increased inflammation by stimulating leukocyte recruitment via up-regulation of circulating platelet surface P-selectin expression and the formation of platelet-leukocyte aggregates. It was also associated with further promoting the luminal deposition of platelet-derived regulated on activation normal $\mathrm{T}$ cell expressed and secreted/chemokine (C-C motif) ligand 5 and expression of monocyte chemoattractant protein-1 and vascular cell adhesion molecule 1 in wire-injured carotid arteries. Remarkably, all these inflammatory actions by activated platelets were abrogated by lack of CD40 on injected platelets. Moreover, injection of wild-type platelets inhibited endothelial recovery in wire-injured carotid arteries, but this effect was also abrogated by lack of CD40 on injected platelets. Results suggest that platelet CD40 plays a pivotal role in neointima formation after arterial injury and might represent an attractive target to prevent restenosis after vascular interventions. (Am J Pathol 2018, 188: 252-263; https://doi.org/10.1016/j.ajpath.2017.09.007)
\end{abstract}

CD40 ligand (CD40L) and its receptor CD40 play a pivotal role in modulating inflammation and immune responses that have been implicated in a variety of human diseases, such as rheumatoid arthritis, multiple sclerosis, diabetes, hypercholesterolemia, atherosclerosis, acute coronary syndromes, and postangioplasty restenosis. ${ }^{1-3}$ The role of CD40L in the development of atherosclerosis has been well established experimentally. Genetic deficiency or antibody inhibition of $\mathrm{CD} 40 \mathrm{~L}$ in atherosclerosis-prone mice [apolipoprotein $\mathrm{E}$ deficient $\left(a p o E^{-/-}\right)$or low-density lipoprotein receptor deficient] not only reduces the atherosclerotic lesion formation but also improves plaque toward a clinically favorable phenotype that was low in inflammatory cells and high in extracellular matrix. $^{4-7}$ However, the role of the receptor CD40 in the development of atherosclerosis is still debatable. Lutgens et $\mathrm{al}^{8}$ have reported that deficiency of hematopoietic CD40 in low-density lipoprotein receptor-deficient mice or genetic interruption of CD40-tumor necrosis factor receptor associated factor 6 (TRAF6) signaling in apoE ${ }^{-/-}$mice reduces atherosclerosis and induces features of plaque stability. In contrast,

Supported by NIH grant NS088719 (G.L.) and the Louisiana State University Health Sciences Foundation Fund for Schumpert Endowed Chair (G.L.).

R.J. and A.Y.X. contributed equally to this work.

Disclosures: None declared. 
Zirlik et $\mathrm{al}^{9}$ have reported that CD40 deficiency in low-density lipoprotein receptor-deficient mice does not ameliorate atherosclerosis. Instead, they postulated an alternative proatherosclerotic interaction of CD40L with integrin macrophage-1 antigen (Mac-1).

Beyond their traditional roles in hemostasis and thrombosis, platelets are now recognized as key mediators of inflammation. ${ }^{10,11}$ Increased platelet activation has been implicated in the development of atherosclerosis and the rupture-prone plaque. $^{12,13}$ In apoE $^{-/-}$mice, repeated injections of thrombin-activated wild-type platelets exacerbated atherosclerosis by promoting circulating plateletleukocyte aggregation and platelet-mediated recruitment of leukocytes to atherosclerosis-prone sites of arteries. ${ }^{14,15}$ Moreover, this platelet-induced exacerbation of atherosclerosis was completely prevented in apoE ${ }^{-1-}$ mice that were injected with platelets deficient in either CD40L or its receptor CD40. ${ }^{14,15}$ Taken together, these studies indicate that activated platelets, as well as platelet CD40 or platelet CD40L, are critical in the development of atherosclerosis. However, the direct impact of activated platelets and platelet CD40/CD40L on neointima formation after arterial injury has not yet been defined.

CD40L is abundantly expressed by activated platelets. It has been reported that activated platelets are the primary source of elevated levels of soluble CD40L in the circulation, with $>95 \%$ of circulating soluble CD40L calculated to originate from platelets. ${ }^{16,17}$ Elevated levels of circulating soluble CD40L have been reported in patients with hypercholesterolemia, diabetes, and acute coronary syndromes, and they predict increased restenosis after angioplasty and stenting. ${ }^{18-22}$ Clinical restenosis is characterized, in part, by substantial accumulation of monocytes/macrophages that exacerbates neointimal lesions. We have previously shown that antibody blockade of $\mathrm{CD} 40 \mathrm{~L}$ reduces neointima formation accompanied by decreased macrophage content in apoE $\mathrm{E}^{-1-}$ mice after carotid artery wire injury. ${ }^{23}$ Although previous studies have suggested the involvement of elevated circulating CD40L (including platelet surface CD40L) in neointima formation in an atherogenic environment, clinical trials have indicated that blockade of CD40L may not be therapeutically feasible. $^{24,25}$ It may cause thromboembolic complications, particularly related to enhanced platelet aggregation, via direct binding of soluble $\mathrm{CD} 40 \mathrm{~L}$ or platelet surface $\mathrm{CD} 40 \mathrm{~L}$ to platelet $\alpha \operatorname{IIb} \beta 3$. Indeed, experimental data showed that platelets deficient in CD40L form less stable platelet aggregates ${ }^{16}$ and pose an increased risk for thromboembolic events. ${ }^{24}$ Such limitations have led researchers to pursue alternative approaches, with encouraging results from several laboratories, including our own, that indicate CD40 or its signaling intermediates as a promising target to suppress atherosclerosis and neointima formation after arterial injury. ${ }^{26-29}$ Our aim was to determine the roles of circulating activated platelets and platelet CD40 in vascular inflammation and neointima formation and to elucidate potential mechanisms involved in atherosclerosis-prone mice after carotid artery wire injury.

\section{Materials and Methods}

\section{Mice}

$\mathrm{CD} 40^{-/-} \mathrm{apoE}^{-/-}$and $\mathrm{CD}^{-10 \mathrm{~L}^{-1-}} \mathrm{apoE}^{-/-}$mice were generated by interbreeding $\mathrm{CD} 40^{-1-}$ and $\mathrm{CD} 40 \mathrm{~L}^{-/-}$mice (The Jackson Laboratory, Bar Harbor, ME), respectively, with $\mathrm{apoE}^{-l-}$ mice (The Jackson Laboratory), all on a C57Bl/6 background. The genotypes were confirmed by PCR of tail snip DNA. All mice were fed standard rodent chow throughout the study. All experimental procedures were approved by the Institutional Animal Care and Use Committee at the Louisiana State University Health Sciences Center (Shreveport, LA).

\section{Mouse Carotid Artery Wire Injury Model}

Male apoE ${ }^{-/-}, \mathrm{CD}_{40}{ }^{-/-} \mathrm{apoE}^{-/-}$, or $\mathrm{CD} 40 \mathrm{~L}^{-/-} \mathrm{apoE}^{-/-}$ mice, at the age of 10 to 12 weeks, were anesthetized with a ketamine-xylazine mixture ( 80 to $5 \mathrm{mg} / \mathrm{kg}$, i.p.). Wire denudation injury of the left common carotid artery was induced by three rotational passes of a 0.014-inch flexible angioplasty guidewire, as previously described. ${ }^{23,26}$ Removal of the endothelium was confirmed by in vivo Evan's Blue Dye staining in injured arteries compared with noninjured arteries, as previously described. ${ }^{26}$ Animals were sacrificed at indicated time points after wire injury, and blood and carotid arteries were harvested for further analysis.

\section{Platelet Preparation and Adoptive Transfer}

Blood was obtained from donor mice $\left(\mathrm{CD}_{40} 0^{-1-} \mathrm{apoE}^{-1-}\right.$ or $\mathrm{apoE}^{-l-}$ ) via the retro-orbital plexus. Blood $(500 \mu \mathrm{L})$ per donor mouse was collected in BD Vacutainer Plus Plastic Citrate Tubes (BD Biosciences, San Jose, CA). Platelet-rich plasma was prepared by centrifugation $(86 \times g$ for 8 minutes). Erythrocytes remaining in the platelet-rich plasma were pelleted at $500 \times g$ for 30 seconds, and then platelets were collected from the suspension by centrifugation at $720 \times g$ for 5 minutes. The platelet pellets were washed and resuspended in phosphate-buffered saline ( $\mathrm{pH}$ 7.4) containing $0.1 \%$ bovine serum albumin (BSA). Washed platelets were activated with $0.5 \mathrm{nmol} / \mathrm{L}$ thrombin for 15 minutes, followed by neutralization with an equimolar dose of hirudin. ${ }^{14,15}$ Platelet activation was confirmed by flow cytometric analysis of platelet surface P-selectin. The i.v. injections (via tail vein) of thrombinactivated platelets $\left(5 \times 10^{7} / 20 \mathrm{~g}\right.$ body weight $)$ or vehicle (phosphate-buffered saline/0.1\% BSA) into $\mathrm{Cd}_{4} \mathrm{O}^{-/-} \mathrm{apoE}^{-/-}$ mice were given once every 5 days, ${ }^{14,15}$ starting at 2 days ${ }^{30}$ before surgery.

\section{Histology and Morphometry}

Serial cross sections (5 $\mu \mathrm{m}$ thick) were cut beginning $200 \mu \mathrm{m}$ proximal to the carotid bifurcation. Seven sections (with $120-\mu \mathrm{m}$ intervals) were stained by the Movat ${ }^{31}$ method, as described. 
The area of the lumen, the internal elastic lamina, and the external elastic lamina were measured by planimetry using Image Pro Plus 5.1 (Media Cybernetics, Rockville, MD), essentially as previously described. ${ }^{23,27}$ Intima area is calculated by subtracting lumen area from the area corresponding to the innermost layer of internal elastic lamina, and medial area is determined by subtracting the innermost internal elastic lamina area from the area corresponding to the outermost layer of external elastic lamina. Lumen stenosis is calculated as the ratio of the intimal area/the area inside the original internal elastic lamina. The mean value of intimal area, intima/media ratio, and lumen stenosis is calculated over the seven cross sections of each vessel.

\section{Immunohistochemistry}

Paraffin-embedded cross sections ( $5 \mu \mathrm{m}$ thick) of the common carotid arteries (four to five sections per mouse) were stained with the following antibodies: a goat polyclonal regulated on activation normal $\mathrm{T}$ cell expressed and secreted (RANTES)/ chemokine (C-C motif) ligand (CCL) 5 antibody (C-19; 1:1000; Santa Cruz Biotechnology, Dallas, TX), monocyte chemoattractant protein (MCP)-1/CCL2 (1:1000; Santa Cruz Biotechnology), vascular cell adhesion molecule 1 (VCAM-1; 1:100; Abcam, Cambridge, UK), and anti-polymorphonuclear leukocyte (1:2500; Accurate, Austin, TX) to detect neutrophils; anti-Mac-2 (1:1000; M3/38; Accurate) to detect monocytes/ macrophages; and anti-CD31 (1:50; Abcam) to detect endothelial cells. Isotype-matched antibodies served as negative controls. Staining for RANTES and MCP-1 was visualized using 3,3'-diaminobendizine. Staining for others was visualized using Alexa Fluor 555- or Alexa Fluor 488-conjugated secondary antibodies (1:200; Invitrogen, Carlsbad, CA). For the 3day study, given that neutrophils and Mac-2-positive cells are observed throughout the vessel wall, the number of these leukocytes is counted in all layers per section (magnification, $\times 100$ ), as described previously. ${ }^{32}$ For the 28 -day study, the content of Mac-2-positive cells is quantified in both intima/ media, and data are expressed as the percentage of the total traced intima/media areas, as described previously. ${ }^{27}$

\section{Flow Cytometry}

Samples were run on a multicolor flow cytometry (FACSCanto II; BD Biosciences), and data were analyzed offline using FlowJo software version 9 (FlowJo LLC, Ashland, OR). Blood was collected into heparinized capillary tubes via retroorbital bleeding (one drop per eye) from either side, at 1 hour before and 4 hours after injury, respectively. Erythrocytes were lysed, and cells were fixed using lyse/fix solution (eBioscience, San Diego, CA). An aliquot of $10 \mu \mathrm{L}$ blood was incubated with rat anti-mouse CD16/CD32 (BD FC Block) to block Fc receptors and then stained with the following monoclonal antibodies against CD45-peridinin chlorophyll protein complex (PerCP) (clone 30-F11): Ly6G-fluorescein isothiocyanate (FITC; clone 1A8), CD11b-allophycocyanin (clone
M1/70), CD41-phosphatidylethanolamine (clone MWReg30), and CD62P (clone RB40.34), or respective isotype controls (all from BD Biosciences). Within the CD45-positive events, neutrophils and monocytes were further distinguished by CD11b-allophycocyanin/Ly6G-FITC double labeling. Platelet (CD41)-neutrophil aggregates were calculated from CD41phosphatidylethanolamine/Ly6G-FITC double-positive events, and platelet (CD41)-monocyte aggregates were calculated from CD41-phosphatidylethanolamine-positive, Ly6GFITC-negative events.

To assess the accumulation of leukocytes within the arterial wall, arterial cells were isolated from pooled carotid arteries using an enzymatic disaggregation method, as described previously. ${ }^{23,33}$ Single-cell suspensions were divided into aliquots (approximately $1 \times 10^{5}$ cells per fluorescence-activated cell sorting tube) and incubated with the Fc Block for 10 minutes on ice to prevent nonspecific binding of FC receptors. Blocked cell samples were then stained with the antibodies against CD45-PerCP (clone 30F11), Ly6G-FITC (clone 1A8), Mac-3-FITC (clone M3/ 84), or respective isotype controls. To exclude dead cells, propidium iodide (40 $\mu \mathrm{g} / \mathrm{mL}$; Calbiochem, San Diego, CA) was added to each aliquot immediately before flow cytometry. Propidium iodide-stained cells were excluded from further analysis. The numbers of neutrophils $\left(\mathrm{Ly} 6 \mathrm{G}^{+}\right)$and monocytes/macrophages $\left(\mathrm{Mac}-3^{+}\right)$were calculated by multiplying the number of total leukocytes by the percentage of each subpopulation within the CD45-positive events.

\section{Platelet-Monocyte Coincubation in Vitro and Enzyme- Linked Immunosorbent Assays}

Monocytes were isolated from spleens of apoE $\mathrm{E}^{-/-}$mice using the EasySep Mouse Monocyte Enrichment Kit, according to the instructions of the manufacturer (STEMCELL Technologies, Vancouver, BC, Canada). Flow cytometry showed a purity of $>95 \%$ of proinflammatory monocytes (ie, $\mathrm{CD} 11 \mathrm{~b}+$ Ly $\left.6 \mathrm{C}^{\text {high }}\right)$. In our study, approximately 2 to $3 \times 10^{6}$ monocytes can be obtained from each spleen $\left(60\right.$ to $70 \times 10^{6}$ cells). Isolated monocytes in serum-free Dulbecco's modified Eagle's medium (DMEM)/F-12 were placed in 96-well plates $\left(1 \times 10^{5}\right.$ cells/well) and coincubated (for 24 hours) with thrombin-activated wild-type or CD40-deficient platelets $\left(1 \times 10^{7}\right.$ cells/well $)$ that were prepared from $\mathrm{apoE}^{-1-}$ or $\mathrm{CD} 40^{-1-}$ apoE $^{-l-}$ mice. All coincubations were placed in the humidified incubator at $37^{\circ} \mathrm{C} / 5 \% \mathrm{CO}_{2}$ and constantly stirred at approximately 60 stirs per minute. After 24 hours of coincubation, levels of RANTES, MCP-1, and IL-1 $\beta$ in the supernatants were measured by the enzyme-linked immunosorbent assay using Quantikine Mouse ELISA Kits (R\&D Systems, Minneapolis, MN).

\section{Leukocyte-Endothelial Cell Adhesion Assay}

An adhesion assay was performed essentially as previously described. ${ }^{34}$ C57BL/6 mouse carotid artery endothelial cells 
(C57-6008; Cell Biologics, Chicago, IL) were cultured in 96well plates in DMEM containing 10\% fetal bovine serum and the endothelial growth factor supplement (Sigma, St. Louis, MO). Confluent mouse carotid artery endothelial cells were activated with $10 \mathrm{ng} / \mathrm{mL} \mathrm{IL-1} \beta$ for 2 hours and then incubated with supernatants of activated platelets for 2 hours. Monocytes $\left(1 \times 10^{6}\right.$ cells $\left./ \mathrm{mL}\right)$ were resuspended in DMEM/0.1\% BSA and pretreated for 30 minutes with or without $100 \mu \mathrm{g} / \mathrm{mL}$ of anti-RANTES monoclonal antibody (MAB478) or an isotype control IgG2a (R\&D Systems). After that, $100 \mu \mathrm{L}$ monocyte suspension was added into individual wells and incubated for 1 hour at $37^{\circ} \mathrm{C}, 5 \% \mathrm{CO}_{2}$. Nonadherent cells were then removed by washing six times with DMEM/0.1\% BSA. Adherent cells were fixed with $4 \%$ paraformaldehyde and stained with $1 \%$ crystal violet, followed by air drying and extraction with $10 \%$ acetic acid. Dye uptake was quantified by an enzyme-linked immunosorbent assay plate reader, and results were determined as the mean total absorbance at $570 \mathrm{~nm}$. The surface binding of RANTES to endothelial cells was analyzed by flow cytometry. Briefly, mouse carotid artery endothelial cells were cultured in 6-well plates, grown to confluence, and then treated with $10 \mathrm{ng} / \mathrm{mL} \mathrm{IL}-1 \beta$ for 2 hours. After that, the cells were incubated with supernatants of wild-type platelets or CD40deficient platelets for 2 hours. Then, the cells were gently rinsed with DMEM twice, fixed with $2 \%$ glutardialdehyde, harvested with a rubber policeman, centrifuged twice in fixation buffer, and resuspended in ice-cold fluorescence-activated cell sorting buffer for further analysis by flow cytometry.

\section{Leukocyte Transwell Migration Assay}

A migration assay was performed using Transwell inserts (diameter, $6.5 \mathrm{~mm}$; pore size, $3 \mu \mathrm{m}$; Corning Inc., Corning, NY), as previously described. ${ }^{35}$ The upper surface of the insert membrane was precoated (2 hours) with collagen type I. Monocytes $\left(1 \times 10^{6}\right.$ cells $\left./ \mathrm{mL}\right)$ suspended in DMEM $/ 0.1 \%$ BSA were pretreated for 30 minutes with or without $100 \mu \mathrm{g} / \mathrm{mL}$ of the rat anti-mouse MCP-1 (CCL2/MCP-1 monoclonal antibody) or an isotype control IgG2b (R\&D Systems). After that, $200 \mu \mathrm{L}$ monocyte suspension was added to the upper chamber. The lower chamber contained $500 \mu \mathrm{L}$ of vehicle (DMEM/0.1\% BSA) or supernatants of platelet-monocyte aggregates by coincubation of monocytes $\left(1 \times 10^{6}\right.$ cells $\left./ \mathrm{mL}\right)$ with thrombin-activated wild-type or CD40-deficient platelets $\left(1 \times 10^{8}\right.$ cells $\left./ \mathrm{mL}\right)$. Migration was allowed to proceed for 3 hours. The inserts were then washed with phosphate-buffered saline, and nonmigrated cells remaining on the upper surface of the insert were removed with a cotton swab. The migrated cells on the insert were fixed with methanol, stained with Diff-Quick (Baxter Diagnostics, Inc., Deerfield, IL), and mounted onto glass slides. The number of migrated cells was counted under a light microscope, and the index of migration was calculated as the ratio between the number of cells migrated in response to medium conditioned from monocyte-platelet aggregates and medium alone.

\section{Statistical Analysis}

Data are presented as means \pm SEM and were determined using either two-tailed $t$-test analysis or one-way analysis of variance, followed by Fisher exact test analysis. $P<0.05$ was considered statistically significant.

\section{Results}

\section{Deficiency of CD40, but Not CD40L, Significantly Reduces Neointima Formation after Carotid Artery Wire Injury in Atherosclerosis-Prone Mice}

The role for CD40 in neointima formation after vascular injury in the setting of atherosclerosis with hypercholesterolemia that is prevalent in patients subjected to coronary angioplasty was first investigated. Compared with apoE $\mathrm{E}^{-1-}$ mice as controls, neointimal area and intima/media ratio were markedly reduced in $\mathrm{CD} 40^{-1-} \mathrm{apoE}^{-/-}$mice, but the reductions did not reach statistical significance in $\mathrm{CD} 40 \mathrm{~L}^{-1-}$ $\mathrm{apoE}^{-1-}$ mice (Figure 1). The percentage of luminal stenosis was reduced in both $\mathrm{CD} 40^{-1-} \mathrm{apoE}^{-1-}$ and $\mathrm{CD} 40 \mathrm{~L}^{-1-}$ $\mathrm{apoE}^{-/-}$mice (Figure 1).

\section{Absence of Platelet CD40 Prevents Platelet-Induced Neointima Formation after Carotid Artery Wire Injury in Atherosclerosis-Prone Mice}

To investigate the independent effect of platelet CD40 on neointima formation, $\mathrm{CD} 40^{-/}$apoE $\mathrm{E}^{-1-}$ mice were injected intravenously with thrombin-activated platelets every 5 days, starting 2 days before injury until sacrifice at 28 days after injury. At the end of the experiment, no differences in plasma cholesterol concentrations (vehicle, $528 \pm 31 \mathrm{mg} / \mathrm{dL} ; \mathrm{CD} 40^{+/}$ ${ }^{+}$apoE $^{-/-}, 535 \pm 28 \mathrm{mg} / \mathrm{dL} ; \mathrm{CD} 40^{-1-}$ apoE $^{-/-}, 531 \pm 26 \mathrm{mg} /$ $\mathrm{dL}$ ) or in body weight (vehicle, $24.8 \pm 0.5 \mathrm{~g} ; \mathrm{CD}^{+} 0^{+/+} \mathrm{apoE}^{-/}$ $\left.{ }^{-}, 25.3 \pm 0.4 \mathrm{~g} ; \mathrm{CD} 40^{-1-} \mathrm{apoE}^{-1-}, 25.6 \pm 0.6 \mathrm{~g}\right)$ were observed. Injection of wild-type platelets significantly promoted neointimal lesions by $60 \%$, compared with the vehicletreated group (Figure 2). Remarkably, this platelet-induced promotion of neointima formation was prevented in mice that received CD40-deficient platelets (Figure 2).

\section{Absence of Platelet CD40 Reduces Circulating Platelet Surface P-Selectin Expression and Platelet-Leukocyte Aggregate Formation after Carotid Artery Wire Injury}

Platelets are rapidly activated and form plateletleukocyte aggregates in blood after vascular injury. To investigate the independent effect of platelet CD40 on platelet-leukocyte aggregation, $\mathrm{CD} 40^{-1-} \mathrm{apoE}^{-1-}$ mice were injected intravenously with thrombi-activated platelets, starting 2 days before injury. Blood was collected at 4 hours after injury for flow cytometric analysis. No differences in total leukocytes $\left(\mathrm{CD} 45^{+}\right)$, neutrophils $\left(\mathrm{Ly}_{6 \mathrm{G}}{ }^{+} / \mathrm{CD} 11 \mathrm{~b}^{+}\right)$, monocytes $\left(\mathrm{Ly} 6 \mathrm{G}^{-} / \mathrm{CD} 11 \mathrm{~b}^{+}\right)$, 
A
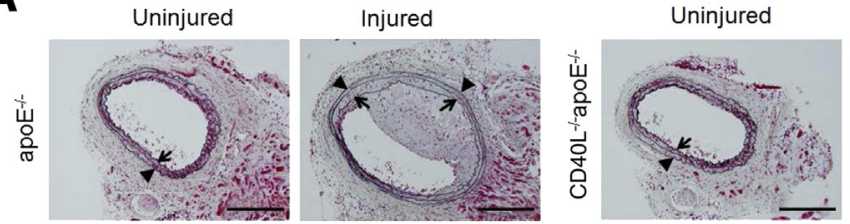

Injured
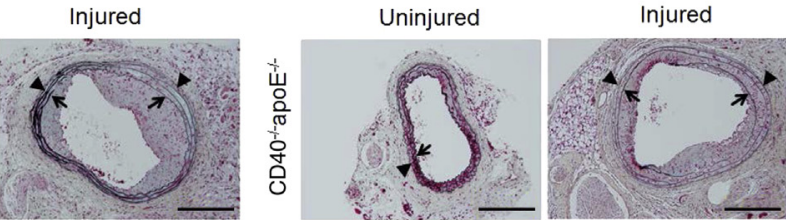

B

C
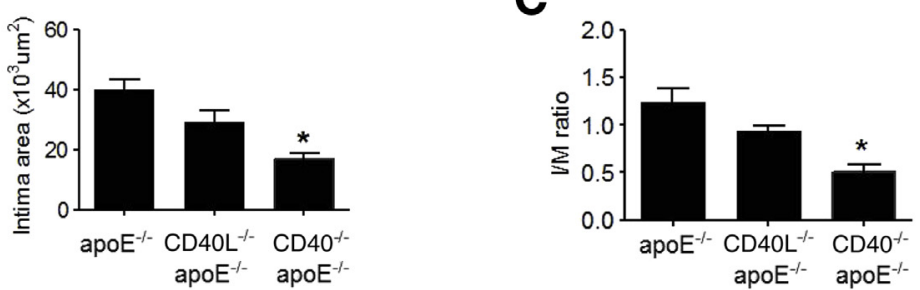

D

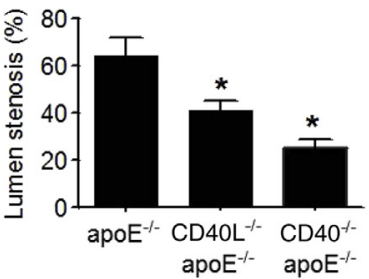

Figure 1 Neointima formation in apoE ${ }^{-/-}, \mathrm{CD} \mathrm{LL}^{-/-} \mathrm{apoE}^{-/-}$, and $\mathrm{CD}^{-1} 0^{-/}$apoE $\mathrm{E}^{-/-}$mice 4 weeks after carotid artery wire injury. Movat ${ }^{31}$ staining was performed on cross sections of carotid arteries. A: Representative microphotographs of contralateral uninjured and injured arteries. Elastic laminae and elastic fibers are highlighted in black by this stain. The innermost layer of internal elastic lamina and the outermost layer of external elastic lamina are indicated by arrows and arrowheads, respectively. B-D: Quantitative measures: neointimal area (B), neointima/media (I/M) ratio (C), and lumen stenosis (D). Data are expressed as means $\pm \mathrm{SEM}(\mathbf{B}-\mathbf{D}) . n=10$ mice per group $(\mathbf{B}-\mathbf{D}) .{ }^{*} P<0.05$ versus apoE ${ }^{-/-}$. Scale bars $=200 \mu \mathrm{m}(\mathbf{A})$.

and $\mathrm{T}$ cells $\left(\mathrm{CD}^{+}\right)$were observed between the vehicle- and platelet-injected groups. Compared with the vehicle-treated group, injection of wild-type platelets (from $a p o E^{-1-}$ mice) significantly enhanced the levels of platelet-neutrophil $\left(\mathrm{CD} 41^{+} \mathrm{Ly}_{6 \mathrm{G}}{ }^{+}\right)$and platelet-monocyte $\left(\mathrm{CD} 41^{+} \mathrm{CD} 11 \mathrm{~b}^{+}\right)$ aggregates in blood (Figure 3, A and B). However, this platelet-enhanced platelet-leukocyte aggregation was abrogated by lack of CD40 on injected platelets (from CD40 $\mathrm{apoE}^{-1-}$ mice) (Figure 3, A and $\mathrm{B}$ ).

Platelet P-selectin is known to mediate the formation of platelet-leukocyte aggregates. To test whether it is involved in the platelet CD40-mediated effect on platelet-leukocyte aggregation, the levels of circulating platelet P-selectin expression in two groups of $\mathrm{CD}_{4} 0^{-1-} \mathrm{apoE}^{-1-}$ mice that were injected with wild-type platelets versus CD40-deficient platelets were examined and compared. Flow cytometric analysis showed that platelet surface P-selectin was comparably detectable in both groups of mice before surgery and significantly increased in both groups at 4 hours after wire injury; however, the wire injury-induced up-regulation of platelet surface P-selectin was profoundly reduced by lack of CD40 on injected platelets (Figure 3, C and D). This finding suggests that platelet CD40 mediates the formation of platelet-leukocyte aggregates, possibly via an indirect effect on platelet P-selectin expression.

\section{Absence of Platelet CD40 Reduces Leukocyte Recruitment to Injured Carotid Arteries}

To further investigate the independent effect of platelet CD40 on platelet-mediated leukocyte recruitment to the injured arterial wall, $\mathrm{CD} 40^{-1-} \mathrm{apoE}^{-/-}$mice were injected intravenously with thrombin-activated platelets, as described in Materials and Methods. Immunohistochemistry showed that injection of activated wild-type platelets, but not CD40deficient platelets, significantly increased both neutrophils and monocytes/macrophages in the injured arteries 3 days after injury, when compared with the vehicle-treated group (Figure 4, A and B). Moreover, flow cytometric analysis was performed to quantify accumulated leukocytes. Injection of wild-type platelets significantly increased both neutrophils and monocytes/macrophages accumulated in the injured
A

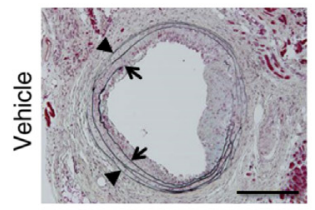

B

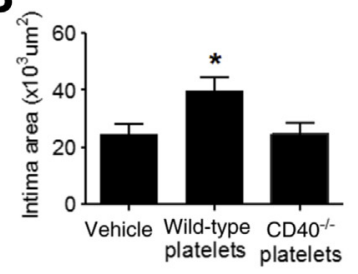

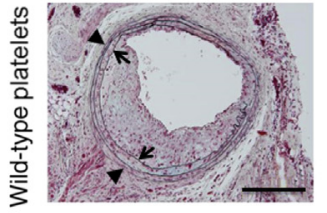

C



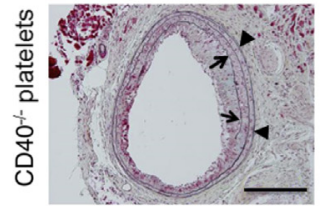

D

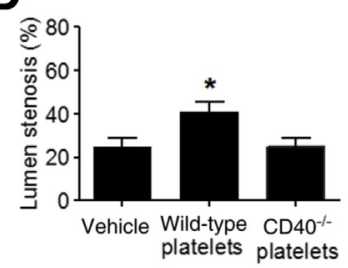

Figure 2 Effect of platelet CD40 on plateletinduced neointima formation 4 weeks after carotid artery wire injury. $\mathrm{CD} 40^{-/-} \mathrm{apoE}^{-/-}$mice were injected with vehicle, wild-type platelets (from $\mathrm{apoE}^{-/-}$mice), or CD40-deficient platelets (from $\mathrm{CD} 0^{-/-} \mathrm{apoE}^{-/-}$mice), as described in Materials and Methods. A: Representative microphotographs of Movat $^{31}$ staining of carotid arteries. The innermost layer of internal elastic lamina and the outermost layer of external elastic lamina are indicated by arrows and arrowheads, respectively. B-D: Quantitative measures: neointima area (B), neointima/media (I/M) ratio (C), and lumen stenosis (D). Data are expressed as means \pm SEM (B-D). $n=10$ mice per group (B-D). ${ }^{*} P<0.05$ versus vehicle. Scale bars $=200 \mu \mathrm{m}(\mathbf{A})$. 
A
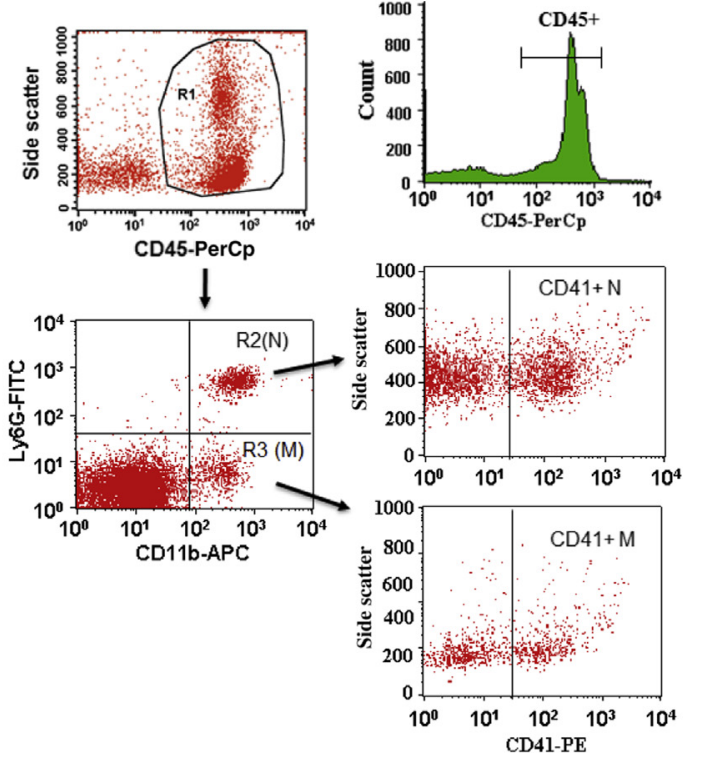

B
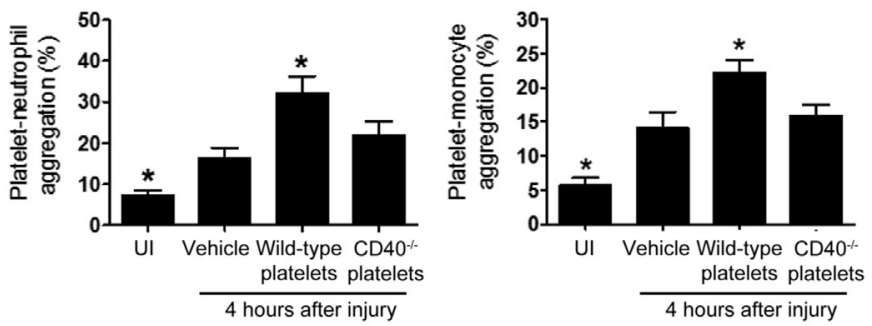
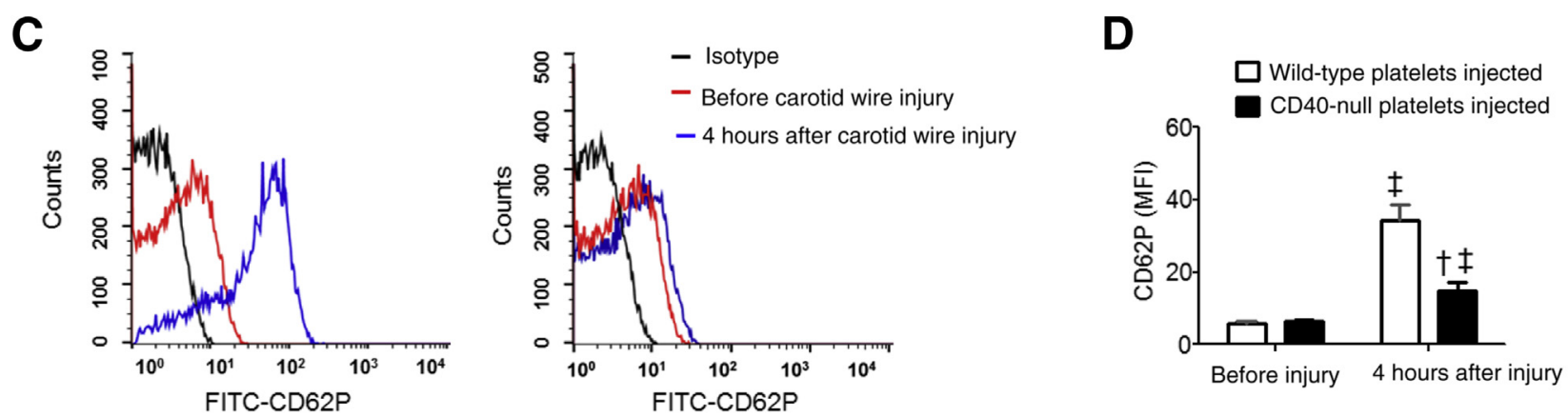

Figure 3 Effect of platelet CD40 on the formation of platelet-leukocyte aggregates in vivo after carotid artery wire injury. A: Gating strategy for flow cytometric analysis of total $\mathrm{CD}_{4} 5^{+}$leukocytes (circle area in R1) in whole blood: neutrophils (N; R2) and monocytes (M; R3) were defined by their differential expression of Ly6G and CD11b. Phosphatidylethanolamine (PE)-labeled CD41 monoclonal antibody was used as a specific platelet marker to identify plateletneutrophil/monocyte complexes. Blood was collected via retro-orbital plexus at 4 hours after wire injury. B: Quantitative analysis of platelet-leukocyte aggregates: $\mathrm{CD}_{4} 1^{+}$neutrophils and $\mathrm{CD}_{4} 1^{+}$monocytes. Injection of platelets into $\mathrm{CD}^{-1} 0^{-/}$apoE $\mathrm{E}^{-/-}$mice was performed 2 days before wire injury. C: Representative histogram of flow cytometry showing P-selectin (CD62P) expression on the platelet surface in blood from two groups of $\mathrm{CD}^{-10^{-/}}$apoE ${ }^{-/-}$mice: injected with wild-type platelets (left panel) or CD40-deficient platelets (right panel), as described in Materials and Methods. Blood was collected at 1 hour before and 4 hours after wire injury. D: Quantitative analysis of platelet surface P-selectin. Data are expressed as mean fluorescence intensity (MFI). $n=5$ to 6 mice per group (B). $n=5$ mice per group (D). ${ }^{\star} P<0.05$ versus vehicle; ${ }^{\dagger} P<0.05$ versus wild-type platelets-injected; ${ }^{\ddagger} P<0.05$ versus respective uninjured controls. APC, allophycocyanin; FITC, fluorescein isothiocyanate; PerCP, peridinin chlorophyll protein complex.

arteries, and this effect was completely abrogated by lack of CD40 on injected platelets (Figure 4C). Infiltrating monocytes/macrophages are an important cellular component of the neointimal lesions in the late phase after arterial injury. ${ }^{36,37}$ Injection of activated wild-type platelets, but not CD40-deficient platelets, significantly increased the monocyte/macrophage content in the neointimal lesions at 28 days after carotid artery wire injury (Figure 4D).

\section{Absence of Platelet CD40 Reduces Leukocyte Recruitment via Inhibition of Inflammatory Chemokine and Adhesion Molecule Expression in the Injured Carotid Arteries}

Last, potential molecular mechanisms of platelet CD40mediated leukocyte recruitment were examined.
Immunohistochemistry showed that injection of activated wild-type platelets, but not CD40-deficient platelets, caused a dramatic increase in the deposition of RANTES/ CCL5 on the luminal surface of the injured carotid artery (Figure 5A) as well as the expression of MCP-1/CCL2 in the media of the carotid artery (Figure 5B) at 3 days after injury. No differences in circulating levels of the chemokines CCL5 and CCL2 were observed between the vehicleand platelet-injected groups (data not shown). Expression of endothelial adhesion molecules (VCAM-1 and intercellular adhesion molecule 1) on recovering endothelium has been implicated in recruiting more monocytes to injured vessels during the late phase of arterial injury. ${ }^{35}$ We observed that injection of activated wild-type platelets, but not CD40-deficient platelets, significantly increased VCAM-1 expression in the luminal lining of the 
A IHC: neutrophils (3 days)
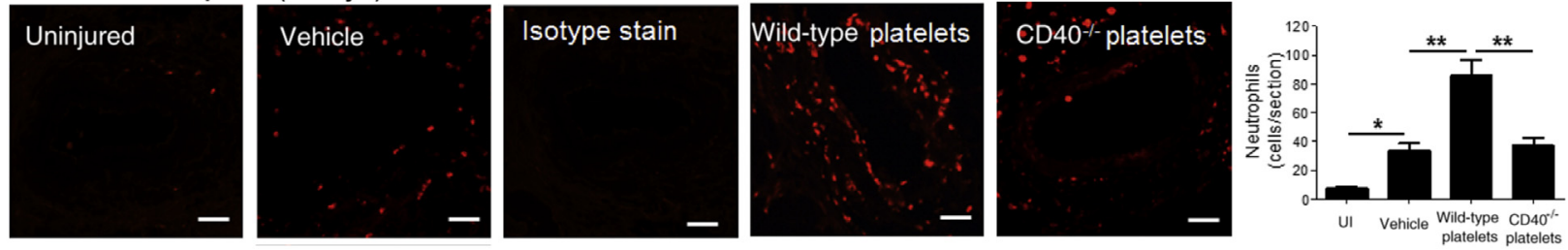

B IHC: monocytes/macrophages (3 days)
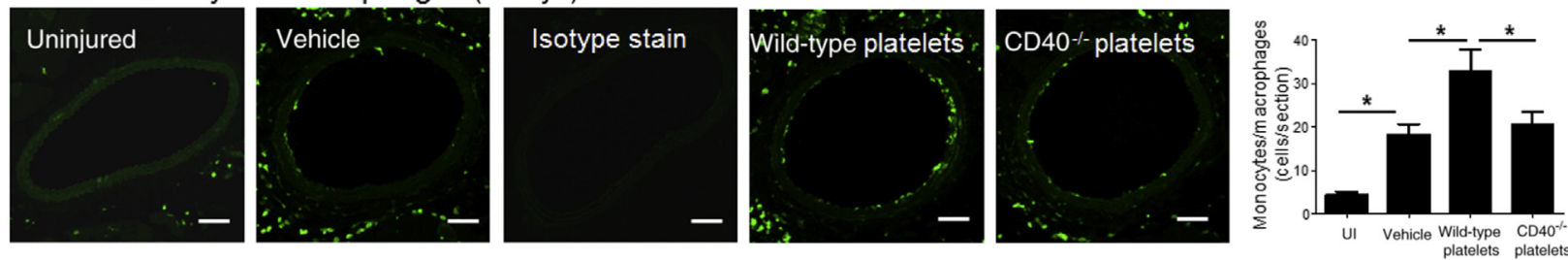

\section{Flow cytometry: mouse carotid arteries ( 3 days)}
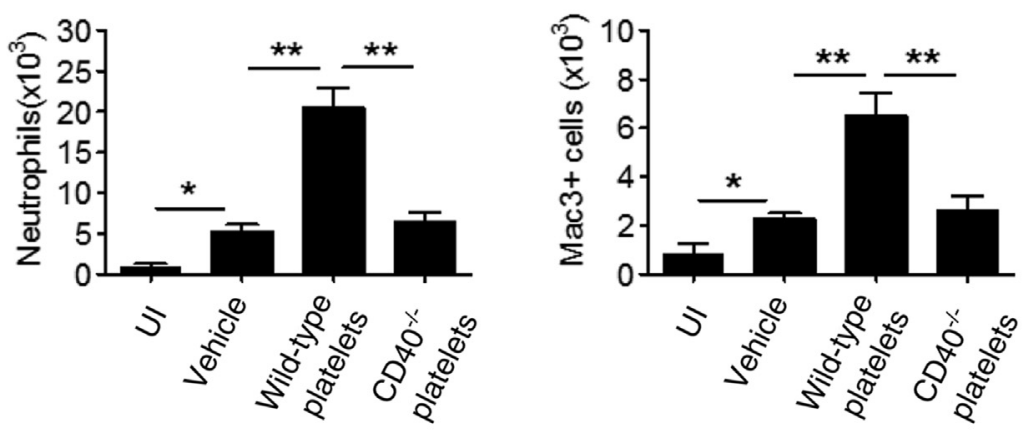

D
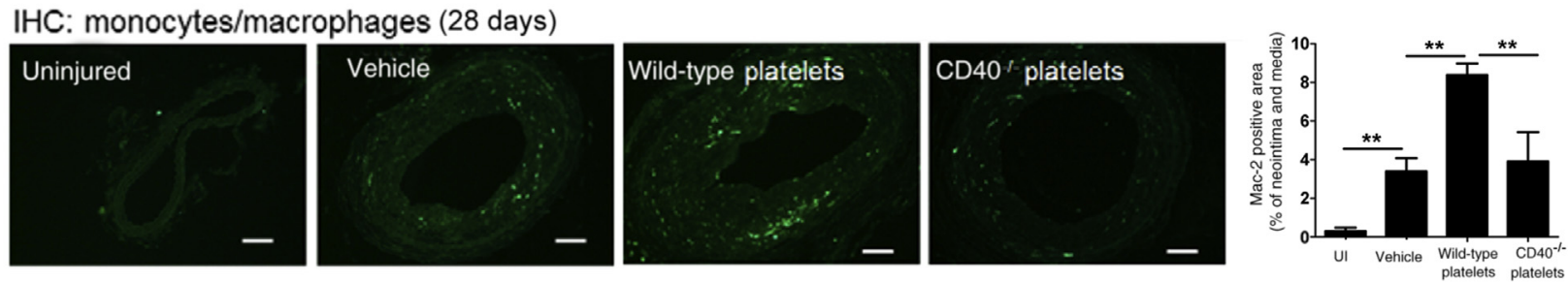

Figure 4 Effect of platelet CD40 on platelet-promoted leukocyte recruitment in injured mouse carotid arteries. A and B: Immunostaining for neutrophils (A) and monocytes/macrophages (B) and semiquantitation in the indicated groups 3 days after wire injury. $\mathrm{CD}_{40} 0^{-/-}$apoE ${ }^{-/-}$mice were injected with vehicle, wild-type platelets (from apoE ${ }^{-1-}$ mice), or CD40-deficient platelets (from $\mathrm{CD}^{-1-} 0^{-}$apoE ${ }^{-/-}$mice), as described in Materials and Methods. C: Quantitative flow cytometric analysis of neutrophils and monocytes/macrophages in mouse carotid arteries 3 days after wire injury, as described in Materials and Methods. D: Immunostaining for monocytes/macrophages and semiquantitation in the indicated groups at 28 days after wire injury. $n=5$ mice per group (A, B, and $\mathbf{D})$. ${ }^{*} P<0.05,{ }^{* *} P<0.01$. Scale bars $=20 \mu \mathrm{m}(\mathbf{A}, \mathbf{B}$, and D). IHC, immunohistochemistry; UI, uninjured.

wire-injured carotid artery at 7 days after injury (Figure 5C).

In vitro, the levels of RANTES/CCL5 in the supernatants of activated wild-type platelets were significantly higher than those in the supernatants of CD40-deficient platelets. However, coincubation with monocytes had no additional effects on RANTES levels (Figure 6A), indicating that RANTES in supernatants was released from activated platelets. Moreover, both MCP-1/CCL2 (Figure 6B) and IL-1 $\beta$ (Figure 6C) in supernatants were released from monocytes that were coincubated with activated platelets, and their release was significantly reduced by lack of platelet CD40. RANTES and MCP-1 are well known to play pivotal roles in mediating monocyte adhesion and chemotaxis, respectively. ${ }^{37}$ Furthermore, in vitro data showed that monocyte adhesion stimulated by supernatants of activated platelets was inhibited by pretreatment of monocytes with anti-RANTES antibody (Supplemental Figure S1), and monocyte chemotaxis induced by supernatants of platelet-monocyte aggregates was inhibited by pretreatment of monocytes with anti-CCR2 antibody (Supplemental Figure S2). 

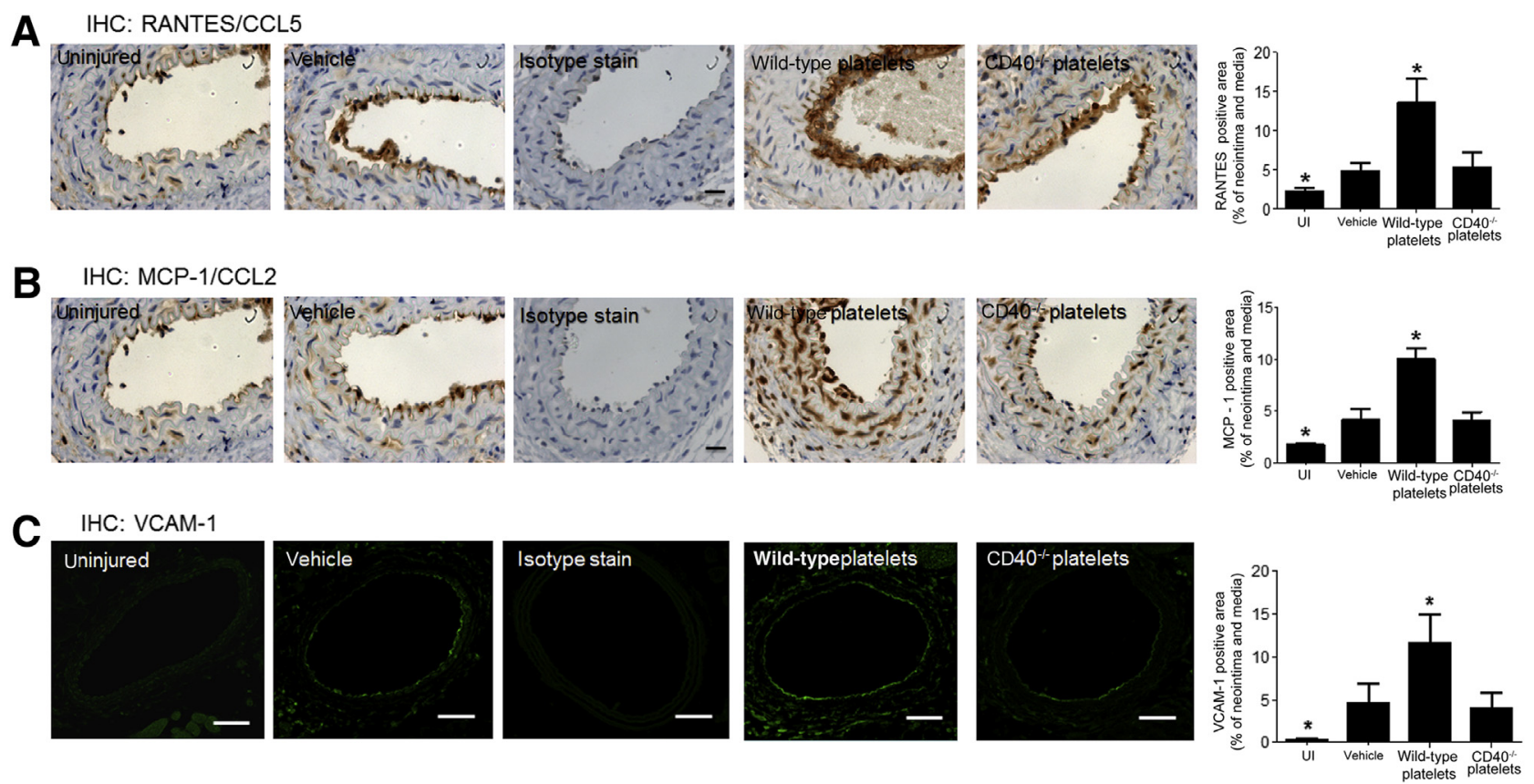

Figure 5 Effect of platelet CD40 on platelet-promoted inflammatory chemokine and adhesion molecule expression in injured mouse carotid arteries. A and B: Immunostaining for regulated on activation normal T cell expressed and secreted/chemokine (C-C motif) ligand 5 (RANTES/CCL5; A) and monocyte chemoattractant protein-1 (MCP-1)/CCL2 (B) and semiquantitation in the indicated groups 3 days after wire injury. RANTES is most prominently seen on the luminal surface, and MCP-1 is seen mainly in the media area, of injured carotid arteries. C: Immunostaining for vascular cell adhesion molecule 1 (VCAM-1) expression and semiquantitation in the indicated groups 7 days after wire injury. Positive staining for VCAM- 1 is shown most prominently in the lumen lining of injured mouse carotid arteries. $n=5$ mice per group (A and B). $n=6$ mice per group (C). ${ }^{\star} P<0.05$ versus vehicle. Scale bars: $20 \mu \mathrm{m}(\mathbf{A}$ and $\mathbf{B}) ; 100 \mu \mathrm{m}$ (C). IHC, immunohistochemistry; UI, uninjured.

\section{Absence of Platelet CD40 Prevents Activated Platelet-Induced Impairment of Endothelial Recovery after Carotid Artery Wire Injury}

Immunostaining for the endothelial marker CD31 was used to determine the presence of endothelial cells in the artery wall. As expected, intact endothelium was shown in normal carotid artery (Figure 7). Recovering endothelium remained minimal at 3 days after wire injury (Figure 7). At 7 days after wire injury, recovering endothelium became evident, with $>75 \%$ endothelial recovery of the lumen circumference in the vehicletreated mice (Figure 7). Obviously, the endothelial recovery was significantly inhibited by injection of activated wild-type platelets, but this inhibitory effect was abrogated by lack of CD40 on injected platelets (Figure 7).

\section{Discussion}

The present study shows, for the first time, that platelet CD40 plays a profound role in driving leukocyte recruitment and neointima formation after carotid artery wire injury. Although considered as a costimulatory system, CD40L and its classic receptor CD40 have different effects on neointima formation after vascular injury. We have recently reported that the deficiency of receptor CD40 significantly reduces neointima formation in different mouse models: carotid artery ligation and femoral artery denudation injury. ${ }^{26-28}$ However, CD40L deficiency has a limited effect on neointima formation in mice after carotid artery ligation. ${ }^{29}$ Herein, we show that deficiency of CD40, but to a much lesser extent CD40L, reduces neointima formation after carotid artery wire injury in atherosclerosis-prone apoE $^{-/-}$mice. Thus, CD40, but not CD40L, might
A

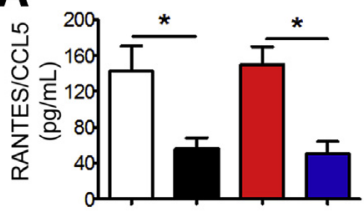

C

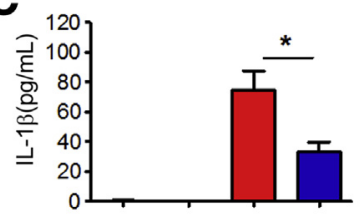

B
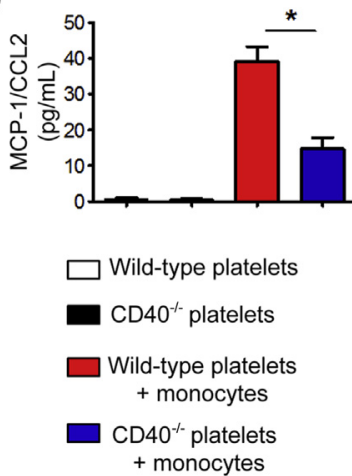

Figure 6 Effect of platelet CD40 on release of proinflammatory mediators by platelet-monocyte aggregates. Regulated on activation normal T cell expressed and secreted/chemokine (C-C motif) ligand 5 (RANTES/CCL5; A), monocyte chemoattractant protein-1 (MCP-1)/CCL2 (B), and IL-1 $\beta$ (C) were measured in the supernatants of platelets alone or platelet-monocyte co-cultures using Quantikine Mouse ELISA Kits. Data are obtained from three independent experiments, each performed in triplicate. ${ }^{*} P<0.05$. 

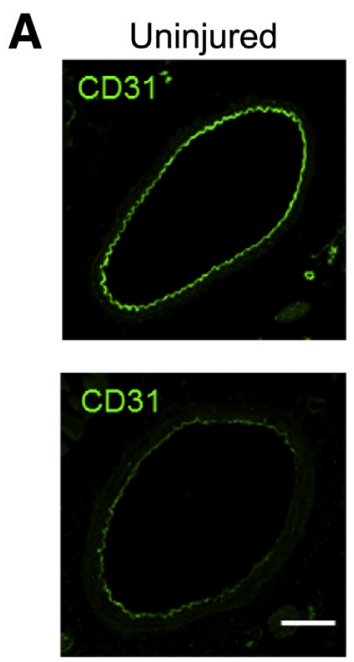

Vehicle
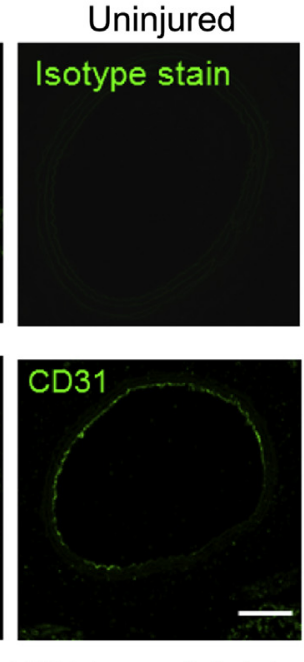

Wild-type platelets
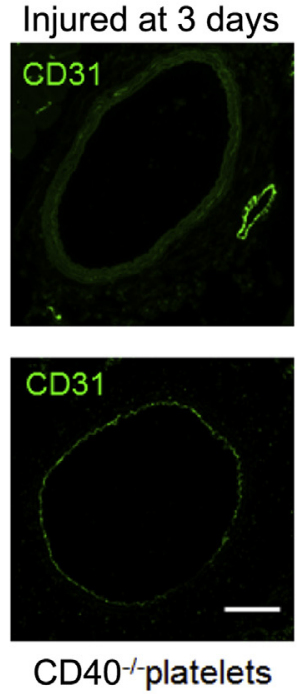

B

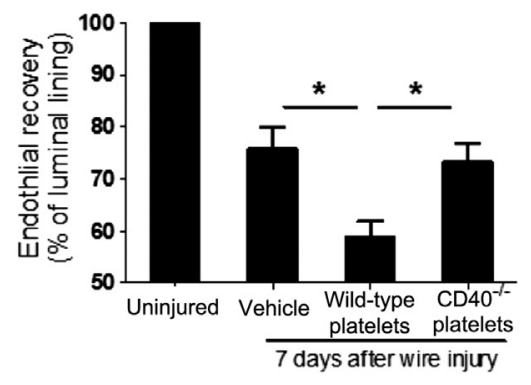

\section{7 days after wire injury}

Figure 7 Effect of platelet CD40 on platelet-induced impairment of the endothelial recovery of wire-injured mouse carotid arteries. Immunostaining for the endothelial marker CD31 was performed to determine the percentage of the luminal endothelial recovery after wire injury. A: Representative images of CD31 staining in both uninjured and injured carotid arteries in the indicated groups. CD40-/- apoE ${ }^{-/-}$mice were injected with vehicle, wild-type platelets, or CD40-deficient platelets, as described in Materials and Methods. Negative control staining with isotype-matched control antibody did not show detectable labeling. B: Quantitative analysis of the endothelial recovery of the wire-injured carotid arteries 7 days after injury. $n=6$ per group $(\mathbf{B})$. ${ }^{\star} P<0.05$. Scale bars $=100 \mu m(\mathbf{A})$.

represent a more valuable therapeutic target to suppress neointima formation after vascular interventions.

A major limitation of experimental research on postinjury neointima formation is that injury was performed on normal arteries of otherwise healthy animals, whereas human restenosis occurs in atherosclerotic arteries. ${ }^{36,37}$ The apoE $\mathrm{E}^{-1-}$ mouse model is well established for the study of human atherosclerosis. The proinflammatory status of $a p o E^{-1-}$ mice makes them good candidates for studying inflammation in cardiovascular diseases, including neointima formation after vascular injury. ${ }^{38}$ The apolipoprotein E-deficient mouse model of carotid artery wire injury has been widely used in numerous publications because it closely mimics the clinical situation in which platelet deposition, inflammatory cell infiltration, and neointima formation developed after balloon angioplasty in patients. ${ }^{36,37}$ In this regard, this model was used in this study to examine the roles of platelets and platelet CD40 in inflammation and neointima formation after arterial injury.

The inflammatory response to acute arterial wall injury has been increasingly recognized to play a decisive role in neointima formation. ${ }^{37}$ We have previously demonstrated that CD40 deficiency reduces neointima formation via suppressing vascular inflammation and oxidative stress after arterial injury. ${ }^{26-28}$ Herein, we further show an important role for CD40 on platelets in neointima formation after carotid artery wire injury, which mainly involves profound effects of platelet CD40 on the formation of circulating platelet-leukocyte formation, the deposition of platelet RANTES/CCL5, and the expression of MCP-1/CCL2 and VCAM-1 in the injured carotid arteries.
Platelet activation in the circulation has also been implicated in increased restenosis rates in patients with coronary angioplasty and stents. ${ }^{39,40}$ Although the role of platelets in the development of thrombosis and abrupt closure after angioplasty and stenting is well recognized, the direct impact of platelets on neointima formation after arterial injury remains poorly understood. Recently, we reported that injection of activated wild-type platelets (from C57B16 mice) increased neointima formation after partial ligation of carotid artery in mice. ${ }^{30}$ In the present study, we further showed the contribution of activated platelets to neointima formation in atherosclerosis-prone apoE-deficient mice after carotid artery wire injury.

One of the mechanisms by which activated platelets mediate inflammatory actions is through the heterotypic interaction with circulating leukocytes, promoting their recruitment and activation. $^{41}$ It has been widely recognized that the formation of platelet-leukocyte heterotypic aggregates is mediated via platelet membrane receptors, such as P-selectin, CD40L, and $\alpha \mathrm{IIb} \beta 3$ that bind P-selectin glycoprotein ligand 1 (PSGL-1), CD40, and CD11b, respectively, on the leukocyte. ${ }^{42}$ In the present study, we demonstrated a significant role for platelet CD40 in circulating platelet-leukocyte (neutrophil and monocyte) aggregation after carotid artery wire injury. This finding is generally consistent with previous in vitro findings. ${ }^{15}$ By performing a coincubation experiment using platelets (isolated from apoE $\mathrm{E}^{-/-}$ or $\mathrm{CD}_{40} 0^{-1-}$ apoE $\mathrm{E}^{-/-}$mice) and splenocytes (isolated from apoE ${ }^{-1-}$ mice), Gerdes et $\mathrm{al}^{15}$ showed that platelet CD40 can bind to neutrophils and monocytes (but not $\mathrm{T}$ cells) and form heterotypic aggregates, but they did not report how platelet CD40 binds to leukocytes. Herein, we demonstrate that platelet 
CD40 mediates the formation of platelet-leukocyte aggregates, possibly via an indirect effect on platelet P-selectin expression.

Despite extensive investigation over two decades, to date, CD40L remains the only ligand identified for CD40. The CD40-CD40L interaction may not account for platelet CD40-mediated formation of platelet-leukocyte aggregates. This is because, by flow cytometry analysis, any significant expression of CD40L was not observed on the surface of neutrophils and monocytes in blood of $\mathrm{apoE}^{-/-}$and $\mathrm{CD} 40^{-/-}$ $\mathrm{apoE}^{-/-}$mice either before or after carotid wire injury. Nevertheless, the possibility that there is another yet unrecognized ligand on leukocytes that can directly bind to CD40 on platelets, thereby mediating the formation of platelet-leukocyte aggregates, cannot be excluded.

RANTES/CCL5 and MCP-1/CCL2, two important members of the CC-chemokine family, are known to be abundantly expressed by activated platelets and monocytes, respectively. They play important roles in mediating monocyte recruitment to the vessel wall in various inflammatory diseases. ${ }^{43}$ Deposition of platelet RANTES has been detected on the luminal surface covering early atherosclerotic or neointimal lesions in carotid arteries of $\mathrm{apoE}^{-/-}$ mice after wire-induced injury. ${ }^{44,45}$ Treatment of $\mathrm{apoE}^{-1-}$ mice with RANTES receptor antagonist Met-RANTES attenuates macrophage infiltration and neointima formation after arterial injury. ${ }^{45}$ Herein, we demonstrate that platelet CD40 mediates leukocyte recruitment via regulation of RANTES and MCP-1.

Monocyte recruitment continuously occurs throughout the time course of vascular repair after injury, and chronic monocyte recruitment is regulated by the interaction with recovering endothelial cells. ${ }^{37}$ Herein, we show the relevance of platelet CD40 in a later phase of monocyte recruitment to sites of vascular injury. Data show that injection of wild-type platelets significantly increases monocyte/macrophage infiltration 28 days after carotid wire injury, and this effect is abrogated by lack of CD40 on injected platelets. VCAM-1 is known as a central mediator of monocyte adhesion to recovering endothelial cells after arterial denudation injury. ${ }^{37}$ IL- $1 \beta$ has been shown to act as a major mediator of platelet-induced activation of the endothelium by inducing endothelial adhesion molecule expression (VCAM-1 and intercellular adhesion molecule 1). ${ }^{46,47}$ In the present study, we show that injection of wild-type platelets can promote the expression of VCAM-1 in recovering endothelium of the injured carotid arteries 7 days after wire injury, and intriguingly, this effect is abrogated by lack of CD40 on injected platelets. Furthermore, in vitro data show that platelet-monocyte cross talk can promote the release of IL$1 \beta$ by activated monocytes, and this effect is attenuated by lack of platelet CD40. Taken together, these findings support an important role for platelet CD40 in promoting endothelial activation and attracting more monocytes toward the sites of injury and inflammation. Moreover, reendothelialization is a critical determinant of neointima formation after arterial injury. ${ }^{48}$ Herein, we show that lack of CD40 on injected platelets can effectively abrogate platelet-induced impairment of endothelial recovery after carotid wire injury.

\section{Limitations}

Platelets have been implicated in multiple pathologic processes of in-stent restenosis involving stent thrombosis, smooth muscle cell proliferation, and endothelial regeneration. ${ }^{40}$ Currently, in-stent restenosis is a major problem of clinical restenosis after angioplasty and stenting, which raises an important concern regarding whether and how platelet CD40 contributes to in-stent restenosis. Indeed, the present study cannot answer this concern. Also, we acknowledge the vast differences between our experimental preparation and human stenting, after which patients are generally treated with potent dual antiplatelet therapy. But, we believe that the results of the present study provide the rationale for further investigation of platelet CD40 in animal models of in-stent restenosis.

\section{Conclusions}

Selective interruption of platelet CD40 will impede platelet-induced inflammatory actions via suppressing plateletleukocyte aggregation and leukocyte recruitment, eventually promoting luminal endothelial recovery and reducing neointima formation after vascular injury. Considering a pivotal role of circulating activated platelets in the process of restenosis and poor prognosis, and an increased risk of thromboembolic events by blocking platelet CD40L, platelet CD40 might represent an attractive therapeutic target for strategies to prevent vascular restenosis.

\section{Acknowledgment}

We thank the animal core facility (Louisiana State University Health Science Center, Shreveport) for help with animal breeding and maintenance.

\section{Supplemental Data}

Supplemental material for this article can be found at https://doi.org/10.1016/j.ajpath.2017.09.007.

\section{References}

1. Hassan GS, Merhi Y, Mourad WM: CD154 and its receptors in inflammatory vascular pathologies. Trends Immunol 2009, 30:165-172

2. Hassan GS, Merhi Y, Mourad W: CD40 ligand: a neo-inflammatory molecule in vascular diseases. Immunobiology 2012, 217:521-532

3. Antoniades C, Bakogiannis C, Tousoulis D, Antonopoulos AS, Stefanadis C: The CD40/CD40 ligand system: linking inflammation with atherothrombosis. J Am Coll Cardiol 2009, 54:669-677 
4. Mach F, Schonbeck U, Sukhova GK, Atkinson E, Libby P: Reduction of atherosclerosis in mice by inhibition of CD40 signalling. Nature 1998, 394:200-203

5. Lutgens E, Gorelik L, Daemen MJ, de Muinck ED, Grewal IS, Koteliansky VE, Flavell RA: Requirement for CD154 in the progression of atherosclerosis. Nat Med 1999, 5:1313-1316

6. Lutgens E, Cleutjens KB, Heeneman S, Koteliansky VE, Burkly LC, Daemen MJ: Both early and delayed anti-CD40L antibody treatment induces a stable plaque phenotype. Proc Natl Acad Sci U S A 2000, 97: 7464-7469

7. Schonbeck U, Sukhova GK, Shimizu K, Mach F, Libby P: Inhibition of CD40 signaling limits evolution of established atherosclerosis in mice. Proc Natl Acad Sci U S A 2000, 97:7458-7463

8. Lutgens E, Lievens D, Beckers L, Wijnands E, Soehnlein O, Zernecke A, Seijkens T, Engel D, Cleutjens J, Keller AM, Naik SH, Boon L, Oufella HA, Mallat Z, Ahonen CL, Noelle RJ, de Winther MP, Daemen MJ, Biessen EA, Weber C: Deficient CD40-TRAF6 signaling in leukocytes prevents atherosclerosis by skewing the immune response toward an antiinflammatory profile. J Exp Med 2010, 207:391-404

9. Zirlik A, Maier C, Gerdes N, MacFarlane L, Soosairajah J, Bavendiek U, Ahrens I, Ernst S, Bassler N, Missiou A, Patko Z, Aikawa M, Schönbeck U, Bode C, Libby P, Peter K: CD40 ligand mediates inflammation independently of CD40 by interaction with Mac-1. Circulation 2007, 115:1571-1580

10. Projahn D, Koenen RR: Platelets: key players in vascular inflammation. J Leukoc Biol 2012, 92:1167-1175

11. Pankratz S, Bittner S, Kehrel BE, Langer HF, Kleinschnitz C, Meuth SG, Göbel K: The inflammatory role of platelets: translational insights from experimental studies of autoimmune disorders. Int J Mol Sci 2016, 17. pii: E1723

12. Linden MD, Jackson DE: Platelets: pleiotropic roles in atherogenesis and atherothrombosis. Int J Biochem Cell Biol 2010, 42:1762-1766

13. Fuentes QE, Fuentes QF, Andrés V, Pello OM, de Mora JF, Palomo GI: Role of platelets as mediators that link inflammation and thrombosis in atherosclerosis. Platelets 2013, 24:255-262

14. Lievens D, Zernecke A, Seijkens T, Soehnlein O, Beckers L, Munnix IC, Wijnands E, Goossens P, van Kruchten R, Thevissen L, Boon L, Flavell RA, Noelle RJ, Gerdes N, Biessen EA, Daemen MJ, Heemskerk JW, Weber C, Lutgens E: Platelet CD40L mediates thrombotic and inflammatory processes in atherosclerosis. Blood 2010, 116:4317-4327

15. Gerdes N, Seijkens T, Lievens D, Kuijpers MJ, Winkels H, Projahn D, Hartwig H, Beckers L, Megens RT, Boon L, Noelle RJ, Soehnlein O, Heemskerk JW, Weber C, Lutgens E: Platelet CD40 exacerbates atherosclerosis by transcellular activation of endothelial cells and leukocytes. Arterioscler Thromb Vasc Biol 2016, 36:482-490

16. Andre P, Prasad KS, Denis CV, He M, Papalia JM, Hynes RO, Phillips DR, Wagner DD: CD40L stabilizes arterial thrombi by a beta3 integrin-dependent mechanism. Nat Med 2002, 8:247-252

17. Prasad KS, Andre P, He M, Bao M, Manganello J, Phillips DR: Soluble CD40 ligand induces beta 3 integrin tyrosine phosphorylation and triggers platelet activation by outside-in signaling. Proc Natl Acad Sci U S A 2003, 100:12367-12371

18. Kopp CW, Steiner S, Nasel C, Seidinger D, Mlekusch I, Lang W, Bartok A, Ahmadi R, Minar E: Abciximab reduces monocyte tissue factor in carotid angioplasty and stenting. Stroke 2003, 34: $2560-2567$

19. Garlichs CD, Johm S, Schmeisser Eskafi S, Goppelt-Struebe M, Schmieder R, Daniel WG: Upregulation of CD40 and CD40 ligand (CD154) in patients with moderate hypercholesterolemia. Circulation 2001, 104:2395-2400

20. Sanguigni V, Pignatelli P, Lenti L, Ferro D, Bellia A, Carnevale R, Tesauro M, Sorge R, Lauro R, Violi F: Short-term treatment with atorvastatin reduces platelet CD40 ligand and thrombin generation in hypercholesterolemic patients. Circulation 2005, 111:412-419

21. Cipollone F, Chiarelli F, Davi G, Ferri C, Desideri G, Fazia M, Iezzi A, Santilli F, Pini B, Cuccurullo C, Tumini S, Del Ponte A, Santucci A, Cuccurullo F, Mezzetti A: Enhanced soluble CD40 ligand contributes to endothelial cell dysfunction in vitro and monocyte activation in patients with diabetes mellitus: effect of improved metabolic control. Diabetologia 2005, 48:1216-1224

22. Heeschen C, Dimmeler S, Hamm CW, van den Brand MJ, Boersma E, Zeiher AM, Simoons ML; CAPTURE Study Investigators: Soluble CD40 ligand in acute coronary syndromes. N Engl J Med 2003, 348:1104-1111

23. Li G, Sanders JM, Bevard MH, Sun Z, Chumley JW, Galkina EV, Ley K, Sarembock IJ: CD40 ligand promotes Mac-1 expression, leukocyte recruitment, and neointima formation after vascular injury. Am J Pathol 2008, 172:1141-1152

24. Kawai T, Andrews D, Colvin RB, Sachs DH, Cosimi AB: Thromboembolic complications after treatment with monoclonal antibody against CD40 ligand. Nat Med 2000, 6:114

25. Prasad KS, Andre P, Yan Y, Phillips DR: The platelet CD40L/GP IIbIIIa axis in atherothrombotic disease. Curr Opin Hematol 2003, 10: 356-361

26. Song Z, Jin R, Yu S, Rivet JJ, Smyth SS, Li G: CD40 is essential in the upregulation of TRAF proteins and NF-kappaB-dependent proinflammatory gene expression after arterial injury. PLoS One 2011, 6: e23239

27. Song Z, Jin R, Yu S, Nanda A, Granger DN, Li G: Crucial role of CD40 signaling in vascular wall cells in neointimal formation and vascular remodeling after vascular interventions. Arterioscler Thromb Vasc Biol 2012, 32:50-64

28. Song Z, Zhu X, Jin R, Wang C, Yan J, Zheng Q, Nanda A, Granger DN, Li G: Roles of the kinase TAK1 in CD40-mediated effects on vascular oxidative stress and neointima formation after vascular injury. PLoS One 2014, 9:e101671

29. Donners MM, Beckers L, Lievens D, Munnix I, Heemskerk J, Janssen BJ, Wijnands E, Cleutjens J, Zernecke A, Weber C, Ahonen CL, Benbow U, Newby AC, Noelle RJ, Daemen MJ, Lutgens E: The CD40-TRAF6 axis is the key regulator of the CD40/CD40L system in neointima formation and arterial remodeling. Blood 2008, 111:4596-4604

30. Wang C, Jin R, Nanda A, Yan J, Li G: Platelet PI $3 \mathrm{~K} \gamma$ contributes to carotid intima-media thickening under severely reduced flow conditions. PLoS One 2015, 10:e0129265

31. Movat HZ: Demonstration of all connective tissue elements in a single section; pentachrome stains. AMA Arch Pathol 1955, 60:289-295

32. Ho YC, Wu ML, Su CH, Chen CH, Ho HH, Lee GL, Lin WS, Lin WY, Hsu YJ, Kuo CC, Wu KK, Yet SF: A novel protective function of 5-methoxytryptophan in vascular injury. Sci Rep 2016, 6:25374

33. Hay C, Micko C, Prescott MF, Liau G, Robinson K, De Leon H: Differential cell cycle progression patterns of infiltrating leukocytes and resident cells after balloon injury of the rat carotid artery. Arterioscler Thromb Vasc Biol 2001, 21:1948-1954

34. Green TD, Park J, Yin Q, Fang S, Crews AL, Jones SL, Adler KB: Directed migration of mouse macrophages in vitro involves myristoylated alanine-rich C-kinase substrate (MARCKS) protein. J Leukoc Biol 2012, 92:633-639

35. Ancuta P, Rao R, Moses A, Mehle A, Shaw SK, Luscinskas FW, Gabuzda D: J Exp Med 2003, 197:1701-1707

36. Jeremy JY, Thomas AC: Animal models for studying neointima formation. Curr Vasc Pharmacol 2010, 8:198-219

37. Schober A, Weber C: Mechanisms of monocyte recruitment in vascular repair after injury. Antioxid Redox Signal 2005, 7:1249-1257

38. Lo Sasso G, Schlage WK, Boué S, Veljkovic E, Peitsch MC, Hoeng J: The Apoe-/- mouse model: a suitable model to study cardiovascular and respiratory diseases in the context of cigarette smoke exposure and harm reduction. J Transl Med 2016, 14:146

39. Papapanagiotou A, Daskalakis G, Siasos G, Gargalionis A, Papavassiliou AG: The role of platelets in cardiovascular disease: molecular mechanisms. Curr Pharm Des 2016, 22:4493-4505

40. Chandrasekar B, Tanguay JF: Platelets and restenosis. J Am Coll Cardiol 2000, 35:555-562

41. van Gils JM, Zwaginga JJ, Hordijk PL: Molecular and functional interactions among monocytes, platelets, and endothelial cells and their 
relevance for cardiovascular diseases. J Leukoc Biol 2009, 85: 195-204

42. Totani L, Evangelista V: Platelet-leukocyte interactions in cardiovascular disease and beyond. Arterioscler Thromb Vasc Biol 2010, 30: $2357-2361$

43. Griffith JW, Sokol CL, Luster AD: Chemokines and chemokine receptors: positioning cells for host defense and immunity. Annu Rev Immunol 2014, 32:659-702

44. von Hundelshausen P, Weber KS, Huo Y, Proudfoot AE, Nelson PJ, Ley K, Weber C: RANTES deposition by platelets triggers monocyte arrest on inflamed and atherosclerotic endothelium. Circulation 2001, 103:1772-1777

45. Schober A, Manka D, von Hundelshausen P, Huo Y, Hanrath P, Sarembock IJ, Ley K, Weber C: Deposition of platelet RANTES triggering monocyte recruitment requires P-selectin and is involved in neointima formation after arterial injury. Circulation 2002, 106: $1523-1529$

46. Beaulieu LM, Lin E, Mick E, Koupenova M, Weinberg EO, Kramer CD, Genco CA, Tanriverdi K, Larson MG, Benjamin EJ, Freedman JE: Interleukin 1 receptor 1 and interleukin $1 \beta$ regulate megakaryocyte maturation, platelet activation, and transcript profile during inflammation in mice and humans. Arterioscler Thromb Vasc Biol 2014, 34:552-564

47. Hawrylowicz CM, Howells GL, Feldmann M: Platelet-derived interleukin 1 induces human endothelial adhesion molecule expression and cytokine production. J Exp Med 1991, 174:785-790

48. Versari D, Lerman LO, Lerman A: The importance of reendothelialization after arterial injury. Curr Pharm Des 2007, 13:1811-1824 